\title{
Incidência de vírus em videiras no Nordeste brasileiro e caracterização molecular parcial de isolados virais locais
}

\author{
Incidence of viruses in grapevines in the Brazilian Northeast \\ and partial molecular characterization of local virus isolates
}

\author{
Aricléia de Moraes Catarino ${ }^{\mathrm{I}}$ Thor Vinícius Martins Fajardo ${ }^{\mathrm{I}}$ \\ Gilvan Pio-Ribeiro ${ }^{\mathrm{I}}$ Marcelo Eiras ${ }^{\mathrm{III}}$ Osmar Nickel ${ }^{\mathrm{II}}$
}

\section{RESUMO}

Os objetivos deste trabalho foram identificar as espécies virais presentes em vinhedos comerciais de duas regiões do Nordeste do Brasil e realizar a caracterização molecular parcial de isolados de três espécies virais. A diagnose foi realizada por meio de RT-PCR em tempo real para a detecção de Grapevine rupestris stem pitting-associated virus (GRSPaV), Grapevine virus A (GVA), Grapevine virus B (GVB), Grapevine leafroll-associated virus 2, 3 e 4 (GLRaV-2, -3 e-4), Grapevine fleck virus (GFkV), Grapevine rupestris vein feathering virus (GRVFV) e Grapevine fanleaf virus (GFLV). Exceto para GFLV, os virus avaliados estão amplamente disseminados nas áreas amostradas, frequentemente em altas incidências e em infecções múltiplas, de até 98\% e 76,4\%, na Zona da Mata e no Vale do São Francisco, respectivamente. Isolados locais de GVA, GVB e GLRaV-3 foram parcialmente caracterizados com base na sequência completa de nucleotideos do gene da proteína capsidial e apresentaram alta porcentagem de identidade de nucleotideos com outros isolados brasileiros: 91,2\% (GVA), 99,8\% (GVB) e 99, 7\% (GLRaV-3).

Palavras-chave: proteina capsidial, levantamento, detecção, variabilidade, Vitis.

\section{ABSTRACT}

The objectives of this study were to identify viral species infecting commercial vineyards in two regions of Northeastern Brazil and perform partial molecular characterization of isolates of three virus species. The diagnosis was performed by real time RT-PCR for detection of GRSPaV, GVA, GVB, GLRaV-2, GLRaV-3, GLRaV-4, GFkV, GRVFV and GFLV. Except for GFLV, the evaluated viruses are widespread in the sampled areas, often in high incidences and in multiple infections, up to $98 \%$ and $76.4 \%$, in the Zona da Mata and in the Vale do São Francisco regions, respectively. Local isolates of GVA, GVB and GLRaV-3, partially characterized by complete coat protein gene nucleotide sequencing, showed high percentage of nucleotide identities with other Brazilian isolates of these viruses: $91.2 \%$ (GVA), $99.8 \%$ $(G V B)$ and $99.7 \%(G L R a V-3)$.

Key words: coat protein, survey, detection, variability, Vitis.

\section{INTRODUÇÃO}

O processo infeccioso causado pelos vírus em videiras (Vitis spp.) resulta em quedas de rendimento e da qualidade da produção e redução da vida útil do vinhedo, refletindo na rentabilidade da cultura. Já foram relatadas, no mundo, cerca de 60 espécies virais na cultura da videira; algumas apresentam relevância e induzem expressivo impacto econômico em muitas regiões e países, outras não se destacam (MARTELLI, 2012). No Brasil, Grapevine leafroll-associated virus (GLRaV-1, $-2,-3,-5$ e -6), Grapevine virus $A, B$ e $D$ (GVA, GVB e GVD), Grapevine rupestris stem pittingassociated virus (GRSPaV), Grapevine fleck virus (GFkV) e Grapevine fanleaf virus (GFLV) já foram detectados em videira (LIMA \& FAJARDO, 2012). Recentemente, CATARINO et al. (2013) identificaram GLRaV-4 e Grapevine rupestris vein feathering virus (GRVFV) em amostras de videiras comercialmente introduzidas no Brasil.

A propagação vegetativa da videira facilita a disseminação e favorece a ocorrência de doenças complexas pelo acúmulo de diferentes espécies e estirpes virais em uma mesma planta (MARTELLI,

'Departamento de Agronomia, Universidade Federal Rural de Pernambuco (UFRPE), Recife, PE, Brasil.

IIEmbrapa Uva e Vinho, CP 130, 95700-000, Bento Gonçalves, RS, Brasil. E-mail: thor.fajardo@embrapa.br. *Autor para correspondência.

IIIInstituto Biológico, Centro de Pesquisa e Desenvolvimento de Sanidade Vegetal, São Paulo, SP, Brasil. 
2012). No Nordeste brasileiro, encontram-se áreas produtoras de uva, destacando-se dois polos: o do Vale do São Francisco, com cerca de 10.000ha, que inclui vinhedos situados nos Estados de Pernambuco e Bahia e o da Zona da Mata, com cerca de 600ha, que abrange municípios de Pernambuco e da Paraíba, ambos com grande potencial de expansão da produção (PROTAS \& CAMARGO, 2011).

Em áreas tropicais, a exemplo do Nordeste do Brasil, onde a videira é cultivada com pequeno período de repouso para permitir mais de uma safra por ano, a temperatura normalmente é elevada e os sintomas característicos das viroses tendem a estar ausentes ou são pouco evidentes. Estes fatos dificultam a avaliação visual de campo da ocorrência e da influência dessas doenças nos parreirais, indicando maior necessidade de se aplicar testes diagnósticos com elevada sensibilidade e especificidade para se conhecer a sanidade do material. Além das condições ambientais, os sintomas de infecção viral em videira podem variar em função do estádio fenológico e da condição nutricional da planta e, também, da combinação envolvendo a cultivar e/ou espécie da hospedeira com a estirpe e/ou espécie viral (LIMA \& FAJARDO, 2012). Assim, muitos vírus podem passar despercebidos por não induzirem sintomas visualmente perceptíveis ou facilmente distinguíveis.

A disponibilidade de informação sobre a incidência de vírus em vinhedos no Brasil ainda é escassa, sobretudo em regiões vitícolas do Nordeste do País. KUHN et al. (2000) identificaram algumas viroses em amostras de vinhedos comerciais do Vale do São Francisco, porém, em alguns casos, sem identificar as espécies virais envolvidas na infecção. Em relação à ocorrência de viroses em videiras na Zona da Mata de Pernambuco e da Paraíba, não há nenhuma informação disponível. Os objetivos deste trabalho foram determinar a incidência de viroses em duas regiões vitícolas localizadas no Nordeste brasileiro, além de caracterizar alguns isolados virais dessas regiões.

\section{MATERIAL E MÉTODOS}

O levantamento de vírus foi realizado em vinhedos comerciais de duas regiões vitícolas, Zona da Mata (municípios de São Vicente Férrer-PE e Natuba-PB) e Vale do São Francisco (municípios de Petrolina-PE, Lagoa Grande-PE e Casa Nova-BA), entre setembro de 2012 e março de 2013. Na Zona da Mata, foram coletadas 50 amostras de videiras com 4 a 40 anos, da cv. 'Isabel' (V. labrusca), plantadas em pé franco ou sobre os porta-enxertos IAC $(313,572)$, em seis propriedades. No Vale do São Francisco, foram coletadas 51 amostras de videiras ( $\boldsymbol{V}$. vinifera) com 2 a 11 anos, das cvs. 'Christmas Rose', Sugraone, 'Crimson Seedless', 'Red Globe', 'Sable', Italia, Thompson Seedless, Midnight Beauty, Shiraz, Tempranillo, Barbera, Cabernet Sauvignon, Petite Shiraz e Ruby Cabernet, enxertadas sobre os portaenxertos IAC (313, 572, 766), Harmony, P1103, SO4 e Richter, em dez propriedades. As amostras foram avaliadas quanto à presença de Foveavirus: GRSPaV; Vitivirus: GVA, GVB; Closterovirus: GLRaV-2; Ampelovirus: GLRaV-3, GLRaV-4; Maculavirus: GFkV; Marafivirus: GRVFV e Nepovirus: GFLV por RT-PCR em tempo real (TaqMan).

A extração de RNA total, a partir de 100 mg de fragmentos do lenho de ramos maduros de videiras, foi realizada triturando-se o tecido vegetal em nitrogênio líquido, e seguindo o protocolo definido no método de adsorção em sílica (ROTT \& JELKMANN, 2001). Videira comprovadamente sadia foi utilizada como controle negativo e, como controle positivo das reações, foi utilizado RNA extraído de videiras mantidas em casa de vegetação, infectadas com isolados das espécies virais avaliadas.

Os oligonucleotídeos e as sondas utilizados nas reações de RT-PCR em tempo real foram desenhados com base em trabalhos publicados: GRSPaV, GVA, GVB (OSMAN \& ROWHANI, 2008); GLRaV-2, GLRaV-3, GLRaV-4 (OSMAN et al., 2007); GFkV e GFLV (DUBIELA et al., 2013). Para o GRVFV, estes reagentes foram definidos neste trabalho para a amplificação de fragmentos de 104 pb, referentes à porção genômica correspondente à proteína capsidial (CP) do GRVFV: oligonucleotídeos 104F (5'AAGAAGCTGACGGATCCTTTCCGC3'), 104R (5'ACGCAGTGGAGGGTGACAGGATTG3') e sonda 104P(5'CGAAATCACCCAGCTGGAGGT GGTTCTCATGCC3').

Todas as sondas foram marcadas na extremidade 5' com os fluoróforos 6-FAM ou VIC para permitir a detecção simultânea de dois vírus na mesma amostra e com TAMRA, fluoróforo que funciona como bloqueador, na extremidade 3 '. As condições das reações de RT-PCR em tempo real foram descritas previamente (DUBIELA et al., 2013), consistindo em ensaios do tipo presença/ausência, utilizando-se o kit TaqMan Master Mix One-Step RT$P C R$ e o termociclador StepOnePlus Real-time PCR System (Applied Biosystems). Os dados das reações foram analisados quantitativamente e graficamente, utilizando-se o StepOne Software v2.3 (Applied Biosystems), pela determinação do $\mathrm{Cq}$ (ciclo quantitativo). Valores de $\mathrm{Cq}$ abaixo de 35 representam resultados positivos, sendo que, quanto maior a concentração viral naamostra, menor será ovalordoCq. 
A caracterização molecular parcial foi desenvolvida por meio da análise da sequência de nucleotídeos de três importantes espécies virais (GVA, GVB e GLRaV-3), cujos isolados foram detectados no levantamento. Os oligonucleotídeos para a amplificação por RT-PCR convencional foram definidos com base em trabalhos anteriores ou definidos neste trabalho: GVA-v1 (F) (5'ATGGCACACTACGCCAAGAGGG3') e C1197 (R) para GVA (FAJARDO et al., 2003); GVB6445 (F) e GVB-7038 (R) para GVB (NICKEL et al., 2002) e LR3-8504 (F) e LR3-9445 (R) para GLRaV-3 (FAJARDO et al., 2007). A síntese do cDNA e as reações de PCR foram conduzidas conforme metodologia descrita por FAJARDO et al. (2003). Os produtos da RT-PCR foram analisados em géis de agarose $1,2 \%$, preparados em tampão TBE $\mathrm{pH} 8,0$, corados com brometo de etídeo e visualizados em transiluminador de luz UV. As bandas observadas, correspondentes a fragmentos de tamanhos esperados, foram recortadas dos géis e eluídas com a utilização do kit Wizard SV Gel and PCR Clean-Up System (Promega).

Os fragmentos de DNA eluídos foram ligados aos vetores pGEM-T Easy (Promega) ou pCR2.1 (Invitrogen). A seguir, as ligações foram utilizadas na transformação de células competentes de Escherichia coli DH5a por meio de choque térmico. O DNA plasmidial das colônias bacterianas transformadas foi extraído utilizando-se o kit Wizard Plus SV Minipreps DNA Purification System (Promega). A confirmação da presença dos fragmentos virais clonados nos plasmídeos recombinantes foi realizada por digestão com a enzima de restrição EcoRI (SAMBROOK \& RUSSEL, 2001). Procedeuse ao sequenciamento automático de nucleotídeos de dois clones por isolado viral caracterizado. As sequências de nucleotídeos obtidas foram traduzidas com auxílio de recurso disponibilizado pelo ExPASy Bioinformatics Resource Portal <http://web.expasy. org/translate/>. Os alinhamentos múltiplos das sequências de nucleotídeos (nt) e de aminoácidos deduzidos (aad) e a geração das matrizes de identidades (de nt e aad) foram realizados com auxílio dos programas Clustal X 1.8 (THOMPSON et al., 1997) e BioEdit 7.1.11. Nas análises, foram incluídas as sequências completas da proteína capsidial (CP) do isolado caracterizado e outros isolados, da mesma espécie viral (GVA, GVB ou GLRaV-3) caracterizados no Brasil, além das sequências do gene $\mathrm{CP}$ do isolado-tipo de cada espécie viral, disponíveis no banco de dados GenBank.

\section{RESULTADOS E DISCUSSÃO}

Foram realizadas análises de RT-PCR em tempo real em 101 amostras de videiras. Os resultados indicam a frequente ocorrência de infecções múltiplas na Zona da Mata (ZM) e no Vale do São Francisco (VSF), com incidências de $0 \%$, $2 \%$ e $98 \%$ (ZM) e $3,9 \%, 19,7 \%$ e $76,4 \%$ (VSF) nas amostras, respectivamente, sadias, infectadas com um vírus e infectadas com mais de um vírus. Em geral, os vírus avaliados encontravam-se amplamente disseminados nas duas regiões amostradas, ZM e VSF, respectivamente, GRSPaV, $80 \%$ e $35 \%$; GVA, $100 \%$ e $61 \%$; GVB, $2 \%$ e $4 \%$; GLRaV- $2,12 \%$ e $2 \%$; GLRaV-3, 62\% e 37\%; GLRaV-4, 90\% e 61\%; GFkV, $32 \%$ e $59 \%$; GRVFV, $0 \%$ e $47 \%$ e GFLV, $0 \%$ em ambas regiões. Estes resultados expandem o conhecimento sobre a incidência e a distribuição de vírus em videiras no Brasil, fornecendo relevante informação para o desenvolvimento de estratégias de controle e manejo destas doenças, com ênfase na importância da utilização de material propagativo de videira livre de vírus na implantação de novos vinhedos. Em diversos países vitícolas, já foram realizados levantamentos de vírus em videiras, por exemplo, na Argentina (VOLPE et al., 2010), no Chile (FIORE et al., 2011), na China (LIU et al., 2013) e nos Estados Unidos (SHARMA et al., 2011). Nestes levantamentos e em outros, a incidência de vírus é bastante variável, dependendo da espécie viral, da cultivar de videira e da região amostrada, entretanto, invariavelmente, atingem expressivos índices, situação semelhante à verificada no levantamento conduzido neste trabalho.

Os sintomas normalmente associados à infecção viral em videira são: perda contínua e gradual do vigor da planta, produção reduzida, coloração (avermelhamento ou amarelecimento) anormal das folhas, folhas com aparência atípica (bordos enrolados, textura rugosa e bolhas na superfície do limbo foliar), brotação, engrossamento e amadurecimento irregulares dos ramos, presença de caneluras no lenho (ranhuras sob a casca do tronco) e casca do tronco com aparência alterada (espessa e com rachaduras), além do amadurecimento irregular da uva, que possui menor teor de açúcares. Sintomas como os relatados foram verificados em muitas das videiras amostradas, indicativos da presença de três importantes viroses: o enrolamento da folha (GLRaV-2, GLRaV-3, GLRaV-4), o lenho rugoso da videira (GVA, GVB, GRSPaV) e a mancha das nervuras $(\mathrm{GFkV})$ e outros vírus associados a essa virose (GRVFV). O único vírus não detectado 
no levantamento foi o GFLV, que, normalmente, apresenta baixa incidência no Brasil (LIMA \& FAJARDO, 2012).

Nem sempre a videira infectada por vírus exibirá sintomas perceptíveis, pois a infecção pode ser latente em algumas cultivares comerciais; entretanto, mesmo nestes casos, a presença do vírus poderá causar prejuízos. Embora os danos provocados por vírus não tenham sido avaliados nos vinhedos amostrados, provavelmente, eles existissem, conforme determinado por outros autores. BASSO et al. (2010) observaram que uvas colhidas de videiras infectadas por vírus apresentaram redução de sólidos solúveis totais de cerca de 3,0 graus Brix, quando comparadas às uvas colhidas de plantas sadias.

GLRaV-3, GLRaV-4, GVA e GVB são transmitidos de maneira semipersistente por cochonilhas, enquanto o GFLV é transmitido por nematoides e GRSPaV, GLRaV-2, GFkV e GRVFV ainda não têm vetores conhecidos. Todos estes vírus são transmitidos por meio da enxertia de material propagativo infectado (MARTELLI, 2012). Em determinados casos, os meios de transmissão podem explicar as incidências obtidas, em outros casos, não há correlação. Por exemplo, foi constatada alta incidência do GRSPaV, entretanto, este vírus não possui vetor conhecido, assim, é provável que sua disseminação tenha se dado pelo uso de material propagativo infectado na formação dos vinhedos amostrados.

A técnica de diagnose, RT-PCR em tempo real, empregada neste trabalho, é extremamente sensível e capaz de superar limitações apresentadas por outras técnicas convencionais de detecção viral. Tais limitações, comumente observadas em videiras, decorrem da distribuição desuniforme do vírus na hospedeira e das expressivas variações do título viral, tanto ao longo do ciclo da planta, quanto nos diferentes tipos de tecidos vegetais (DUBIELA et al., 2013).

O emprego dos oligonucleotídeos GVA-v1/ C1197 permitiu a amplificação de fragmentos de DNA com 625 bp contendo o gene da CP do GVA. O gene completo da proteína capsidial do GVA, isolado IT-BA, com 597 nucleotídeos (198 aminoácidos deduzidos, aad), foi amplificado por RT-PCR a partir da amostra no 91 da cv. 'Italia' de Casa Nova-BA. A sequência de nucleotídeos deste isolado (acesso GenBank KF667501) apresentou identidade entre 89,6-91,2\% quando comparada a outros isolados brasileiros do mesmo vírus (AF494187 do RS e AY340581 de SP) e com o isolado-tipo do GVA (NC_003604). A identidade de aad entre os isolados de GVA analisados foi de $94,9 \%$ a $98,9 \%$ (Tabela 1 ). De modo geral, os critérios para a definição de espécies virais nas famílias
Tabela 1 - Identidade (\%) das sequências de nucleotídeos (abaixo da diagonal) e de aminoácidos deduzidos (acima da diagonal) do gene completo (597 pb, $198 \mathrm{aad}) \mathrm{da}$ proteína capsidial entre diferentes isolados brasileiros de Grapevine virus A.

\begin{tabular}{lcccc}
\hline Isolados & IT-BA & “GVA-RS” & “GVA-SP” & Is 151 \\
\hline IT-BA & --- & 95,4 & 98,9 & 96,9 \\
"GVA-RS" & 89,6 & --- & 94,9 & 95,4 \\
"GVA-SP" & 91,2 & 89,3 & --- & 96,4 \\
Is151 & 89,7 & 90,8 & 91,9 & --- \\
\hline
\end{tabular}

Nome do isolado (código de nucleotídeos / código de aad do isolado no GenBank, País, Estado): IT-BA (KF667501 / AGX27424, Brasil, BA), "GVA-RS" (AF494187 / AAM14605, Brasil, RS), "GVA-SP" (AY340581/ AAQ19964, Brasil, SP), isolado-tipo do GVA: Is151 (NC 003604 / NP 619665, Itália). Em negrito, informação do isolado caracterizado neste trabalho.

Betaflexiviridae e Closteroviridae estabelecem que a sequência de aminoácidos deduzidos das principais ORFs apresente diferença superior a $10 \%$, sendo a sequência do gene da proteína capsidial amplamente utilizada na taxonomia (KING et al., 2012).

O gene completo da proteína capsidial do GVB, isolado IS-SVF, com 594 nucleotídeos (197 aad), foi amplificado por RT-PCR a partir da amostra $\mathrm{n}^{\circ} 15$ da cv. 'Isabel' de São Vicente Férrer-PE. A sequência de nucleotídeos deste isolado (acesso GenBank KF040332) apresentou identidade entre 92,7-99,8\% com os isolados brasileiros do mesmo vírus (KF040331 e AY340583 de SP, KF040333 e AF438410 do RS) e de 81,3-82,7\%, quando comparado com os isolados AY340582, de SP, e com o isolado-tipo do GVB (NC_003602). A identidade de aad entre todos os isolados de GVB analisados variou de $95,4 \%$ a $100 \%$ (Tabela 2 ). Variabilidade entre isolados de GVA e GVB já havia sido verificada (MOREIRA et al., 2004a; MOREIRA et al., 2004b; NICKEL et al., 2002; FAJARDO et al., 2003), entretanto, sem considerar isolados provenientes do Nordeste brasileiro, identificados posteriormente.

O gene completo da proteína capsidial do GLRaV-3, isolado RC-PE, com 942 nucleotídeos e 313 aminoácidos deduzidos, foi amplificado por RTPCR a partir da amostra n ${ }^{\circ} 101$ da cv. 'Ruby Cabernet' de Petrolina-PE. A sequência de nucleotídeos deste isolado (acesso GenBank KJ704369) apresentou identidade entre $99,2-99,7 \%$, com os isolados brasileiros do mesmo vírus (DQ680141, DQ680142, DQ062152 de PE) e com o isolado-tipo do GLRaV-3 (NC_004667) e 92,9-93,4\%, quando comparado com os outros isolados brasileiros Pet-4 (AY753208 de PE) e IS2 (HM059034 do RS). A identidade de aad entre todos os isolados de GLRaV-3 analisados foi de 
Tabela 2 - Identidade (\%) das sequências de nucleotídeos (abaixo da diagonal) e de aminoácidos deduzidos (acima da diagonal) do gene completo (594 pb, 197 aad) da proteína capsidial entre diferentes isolados brasileiros de Grapevine virus B.

\begin{tabular}{|c|c|c|c|c|c|c|c|}
\hline Isolados & IS-SVF & $\mathrm{CO}$ & $\mathrm{CS}$ & BR1 & Common & Italia & "GVB-italiano" \\
\hline IS-SVF & --- & 100 & 100 & 100 & 97,5 & 96,4 & 97,5 \\
\hline $\mathrm{CO}$ & 99,8 & --- & 100 & 100 & 97,5 & 96,4 & 97,5 \\
\hline $\mathrm{CS}$ & 99,8 & 100 & --- & 100 & 97,5 & 96,4 & 97,5 \\
\hline BR1 & 99,8 & 100 & 100 & --- & 97,5 & 96,4 & 97,5 \\
\hline Common & 82,7 & 82,5 & 82,5 & 82,5 & --- & 95,4 & 98,9 \\
\hline Italia & 92,7 & 92,6 & 92,6 & 92,6 & 83,7 & --- & 95,4 \\
\hline "GVB-italiano" & 81,3 & 81,2 & 81,3 & 81,3 & 98,6 & 82,5 & --- \\
\hline
\end{tabular}

Nome do isolado (código de nucleotídeos / código de aad do isolado no GenBank, País, Estado): IS-SVF (KF040332 / AGO86377, Brasil, PE), CO (KF040331 / AGO86376, Brasil, SP), CS (KF040333 / AGO86378, Brasil, RS), BR1 (AF438410 / AAL40797, Brasil, RS), Common (AY340582/ AAQ19965, Brasil, SP), Italia (AY340583/ AAQ19966, Brasil, SP), isolado-tipo do GVB: "GVB-italiano" (NC_003602 / NP_619657, Itália). Em negrito, informação do isolado caracterizado neste trabalho.

$94,9 \%$ a $100 \%$ (Tabela 3). Variabilidade entre isolados de GLRaV-3 já havia sido verificada (FAJARDO et al., 2007), inclusive considerando alguns isolados provenientes do Nordeste brasileiro.

Apesar das variações mais acentuadas terem sido verificadas nas sequências de nucleotídeos, as sequências de aminoácidos deduzidos das proteínas capsidiais tendem a apresentar menor variação entre os isolados de regiões geográficas distintas (Tabelas 1, 2 e 3). A proteína capsidial é uma proteína estrutural, assim, fatores evolutivos poderiam restringir as variações que seriam deletérias para as três espécies virais. Alterações nas proteínas capsidiais poderiam, por exemplo, resultar na perda da capacidade de interação com vetores ou fatores da planta hospedeira e o fato do GVA, GVB e GLRaV-3 terem como única hospedeira natural a videira, poderia restringir ainda mais essas alterações (MOREIRA et al., 2004b).

A videira é uma planta exótica no Brasil. Assim, as espécies virais encontradas infectando, localmente, esta hospedeira, foram originalmente introduzidas com a planta, em um passado distante, ou introduzidas via importação de mudas, em processo mais recente. A viticultura brasileira é resultado da introdução de cultivares de copa e de porta-enxerto oriundas dos Estados Unidos (cultivares e híbridos de Vitis labrusca, por ex., cv. 'Isabel') e de países europeus, como França e Itália (principalmente cultivares de $\boldsymbol{V}$. vinifera). Também, ao longo do tempo, ocorreu grande redistribuição de material propagativo e mudas de videiras entre regiões geográficas do Brasil, podendo isto ter contribuído para a redistribuição dos patógenos virais incidentes (MOREIRA et al., 2004b; PROTAS \& CAMARGO, 2011). Assim sendo, os vírus constatados nas duas regiões amostradas no Nordeste brasileiro teriam chegado até estas regiões pelas vias mencionadas. Em relação à variabilidade genética dos três vírus estudados, foi possível verificar elevados níveis de identidade de aminoácidos deduzidos (94,5\% a 100\%)

Tabela 3 - Identidade (\%) das sequências de nucleotídeos (abaixo da diagonal) e de aminoácidos deduzidos (acima da diagonal) do gene completo (942 pb, $313 \mathrm{aad)}$ da proteína capsidial entre diferentes isolados brasileiros de Grapevine leafroll-associated virus 3.

\begin{tabular}{lccccccc}
\hline Isolados & RC-PE & Pet-1 & Pet-2 & Pet-3 & Pet-4 & IS2 & NY1 \\
\hline RC-PE & --- & 100 & 99,6 & 99,6 & 95,8 & 94,9 & 99,0 \\
Pet-1 & 99,7 & --- & 99,6 & 99,6 & 95,8 & 94,8 \\
Pet-2 & 99,6 & 99,8 & --- & 99,3 & 95,5 & 94,5 \\
Pet-3 & 99,5 & 99,7 & 99,6 & --- & 95,5 & 94,5 \\
Pet-4 & 93,4 & 93,4 & 93,3 & 93,2 & --- & 96,4 \\
IS2 & 92,9 & 92,8 & 92,7 & 92,6 & 97,7 & -- \\
NY1 & 99,2 & 99,4 & 99,3 & 99,2 & 92,8 & 94,7 & 92,3 \\
\hline
\end{tabular}

Nome do isolado (código de nucleotídeos / código de aad do isolado no GenBank, País, Estado): RC-PE (KJ704369 / AID53088, Brasil, PE), Pet-1 (DQ680141 / ABG76780, Brasil, PE), Pet-2 (DQ680142 / ABG76781, Brasil, PE), Pet-3 (DQ062152 / AAY62364, Brasil, PE), Pet-4 (AY753208 / AAV27299, Brasil, PE), IS2 (HM059034 / ADG57581, Brasil, RS), isolado-tipo do GLRaV-3: NY1 (NC_004667 / NP_813801, EUA). Em negrito, informação do isolado caracterizado neste trabalho. 
com outros isolados, previamente caracterizados no Brasil, enfatizando a validade das informações sobre possíveis origens comuns dos materiais propagativos infectados de videira.

A compreensão da diversidade genética da população viral e a determinação da incidência das espécies virais em uma região podem viabilizar a diagnose focada em testes diagnósticos "universais", capazes de detectar um maior número de isolados e estirpes de uma espécie viral, favorecendo a implementação de determinadas práticas de manejo e controle de viroses, além de possibilitarem a realização de estudos epidemiológicos.

\section{CONCLUSÃO}

A determinação da incidência de vírus em duas regiões vitícolas situadas no Nordeste brasileiro; a identificação, caracterização e estudo da variabilidade genética de três isolados virais locais e a robustez demonstrada pelo teste RT-PCR em tempo real para a detecção dos isolados locais, em conjunto, aprofundam o conhecimento de viroses nas regiões estudadas e contribuem para o desenvolvimento de ferramentas de diagnóstico viral mais específicas e sensíveis.

\section{AGRADECIMENTOS}

Ao Marcos F. Vanni (Embrapa Uva e Vinho), Maria Angélica G. Barbosa (Embrapa Semiárido), Selma C. C. H. Tavares (Embrapa Solos) e Genira P. Andrade (UFRPE), pela colaboração em diferentes etapas deste trabalho.

\section{REFERÊNCIAS}

BASSO, M.F. et al. Fisiologia foliar e qualidade enológica da uva em videiras infectadas por vírus. Tropical Plant Pathology, v.35, p.351-359, 2010. Disponível em: $<$ http://dx.doi.org/10.1590/ S1982-56762010000600003>. Acesso em: 22 set. 2014. doi: $10.1590 / \mathrm{S} 1982-56762010000600003$

CATARINO, A.M. et al. Detection and partial molecular characterization of isolates of Grapevine leafroll-associated virus 4 and Grapevine rupestris vein feathering virus. Tropical Plant Pathology, v.38, supl., p.840, 2013.

DUBIELA, C.R. et al. Simultaneous detection of Brazilian isolates of grapevine viruses by TaqMan real-time RT-PCR. Tropical Plant Pathology, v.38, p.158-165, 2013. Disponível em: <http:// dx.doi.org/10.1590/S1982-56762013000200011>. Acesso em: 22 set. 2014. doi: 10.1590/S1982-56762013000200011.

FAJARDO, T.V.M. et al. Detecção de um isolado de Grapevine virus $A$ e caracterização do gene da proteína capsidial. Fitopatologia Brasileira, v.28, p.521-527, 2003. Disponível em: $<$ http://dx.doi.org/10.1590/S0100-41582003000500009>. Acesso em: 22 set. 2014. doi: 10.1590/S0100-41582003000500009.

FAJARDO, T.V.M. et al. Variability of the coat protein gene of Grapevine leafroll-associated virus 3 in Brazil. Fitopatologia
Brasileira, v.32, p.335-340, 2007. Disponível em: <http://dx.doi. org/10.1590/S0100-41582007000400008>. Acesso em: 22 set. 2014. doi: 10.1590/S0100-41582007000400008.

FIORE, N. et al. Grapevine viruses in the Atacama region of Chile. Journal of Phytopathology, v.159, p.743-750, 2011. Disponível em: <http://dx.doi.org/10.1111/j.1439-0434.2011.01834.x>. Acesso em: 22 set. 2014. doi: 10.1111/j.1439-0434.2011.01834.x.

KING, A.M.Q. et al. (Eds). Virus taxonomy: ninth report of the International Committee on Taxonomy of Viruses. San Diego: Elsevier Academic, 2012. 1327p.

KUHN, G.B. et al. Viroses da videira identificadas na Região do Submédio São Francisco no polo vitícola Petrolina/Juazeiro. Fitopatologia Brasileira, v.25, supl., p.442, 2000.

LIMA, M.F.; FAJARDO, T.V.M. Doenças causadas por vírus. In: LIMA, M.F.; MOREIRA, F.R.B. Uva de mesa - Fitossanidade. Série Frutas do Brasil 14. 2.ed. Brasília: Embrapa, 2012. p.43-58.

LIU, M.H. et al. Occurrence of grapevine leafroll-associated viruses in China. Plant Disease, v.97, p.1339-1345, 2013. Disponível em: <http://dx.doi.org/10.1094/PDIS-01-13-0048RE > . Acesso em: 22 set. 2014. doi: 10.1094/PDIS-01-13-0048-RE.

MARTELLI, G.P. Grapevine virology highlights 2010-2012. In: CONGRESS OF THE INTERNATIONAL COUNCIL FOR THE STUDY OF VIRUS AND VIRUS-LIKE DISEASES OF THE GRAPEVINE, 17., 2012, Davis, USA. Proceedings... Davis: ICVG, 2012. p.13-31.

MOREIRA, A.E. et al. Caracterização do gene da proteína capsidial de dois isolados, patologicamente distintos e sorologicamente semelhantes, do Grapevine virus $B$ em videiras no Estado de São Paulo. Fitopatologia Brasileira, v.29, p.7580, 2004a. Disponível em: <http://dx.doi.org/10.1590/S010041582004000100011>. Acesso em: 22 set. 2014. doi: 10.1590/ S0100-41582004000100011.

MOREIRA, A.E. et al. Caracterização do gene da proteína capsidial do Grapevine virus $A$ em videiras afetadas pela acanaladura do lenho de Kober no Estado de São Paulo. Fitopatologia Brasileira, v.29, p.205-208, 2004b. Disponível em: <http://dx.doi. org/10.1590/S0100-41582004000200015>. Acesso em: 22 set. 2014. doi: 10.1590/S0100-41582004000200015.

NICKEL, O. et al. Detection and coat protein gene characterization of an isolate of Grapevine virus B from corky bark-affected grapevines in Southern Brazil. Fitopatologia Brasileira, v.27, p.279-284, 2002. Disponível em: <http://dx.doi.org/10.1590/ S0100-41582002000300007>. Acesso em: 22 set. 2014. doi: 10.1590/S0100-41582002000300007.

OSMAN, F. et al. Real-time RT-PCR (TaqMan) assays for the detection of Grapevine leafroll associated viruses 1-5 and 9. Journal Virological Methods, v.141, p.22-29, 2007. Disponível em: <http://dx.doi.org/10.1016/j.jviromet.2006.11.035>. Acesso em: 22 set. 2014. doi: 10.1016/j.jviromet.2006.11.035.

OSMAN, F.; ROWHANI, A. Real-time RT-PCR (TaqMan) assays for the detection of viruses associated with Rugose wood complex of grapevine. Journal of Virological Methods, v.154, p.69-75, 2008. Disponível em: <http://dx.doi.org/10.1016/j. jviromet.2008.09.005>. Acesso em: 22 set. 2014. doi: 10.1016/j. jviromet.2008.09.005. 
PROTAS, J.F.S.; CAMARGO, U.A. Vitivinicultura Brasileira: Panorama Setorial de 2010. Brasília: SEBRAE; Bento Gonçalves: IBRAVIN: Embrapa Uva e Vinho, 2011. 110p.

ROTT, M.E.; JELKMANN, W. Characterization and detection of several filamentous viruses of cherry: Adaptation of an alternative cloning method (DOP-PCR) and modification of an RNA extraction protocol. European Journal of Plant Pathology, v.107, p.411-420, 2001. Disponível em: <http://dx.doi. org/10.1023/A:1011264400482>. Acesso em: 22 set. 2014. doi: 10.1023/A:1011264400482.

SAMBROOK, J.; RUSSELL, D. Molecular cloning: a laboratory manual. 3.ed. New York: CSHL, 2001. 999p.
SHARMA, A.M. et al. Occurrence of grapevine leafrollassociated virus complex in Napa Valley. PLoS One, v.6, p.e26227, 2011. Disponível em: <http://dx.doi.org/10.1371/ journal.pone.0026227>. Acesso em: 22 set. 2014. doi: 10.1371/ journal.pone.0026227.

THOMPSON, J.D. et al. The Clustal X windows interface: flexible strategies for multiple sequence alignment aided by quality tools. Nucleic Acids Research, v.24, p.4876-4882, 1997.

VOLPE, M.L. et al. Incidence of Grapevine leafroll associated viruses $-1,-2$, and -3 in Mendoza vineyards. Tropical Plant Pathology, v.35, p.377-380, 2010. Disponível em: <http://dx.doi. org/10.1590/S1982-56762010000600007>. Acesso em: 22 set. 2014. doi: 10.1590/S1982-56762010000600007. 